\title{
Thrombin based gelatin matrix and fibrin sealant mediated clot formation in the presence of clopidogrel
}

\author{
Joseph F Dwyer ${ }^{1 *}$, Jill A McCoy ${ }^{1}$, Ziping Yang ${ }^{1}$, Michael Husser ${ }^{1}$, Heinz Redl ${ }^{2}$, Mary Ann Murphy ${ }^{1}$, \\ Martin Wolfsegger ${ }^{3}$, James P DiOrio ${ }^{1}$, Andreas Goppelt ${ }^{3}$ and Shane Donovan ${ }^{1 \wedge}$
}

\begin{abstract}
Background: Platelet inhibitors are commonly used to reduce the risk of atherothrombotic events. The aim of this study was to determine the impact of platelet inhibitors, specifically clopidogrel and aspirin, on clot kinetics, strength, and/or structure during the use of thrombin based gelatin matrices and fibrin sealants.

Methods: Blood was collected and heparinized from donors on clopidogrel (and aspirin) and age matched control donors. Blood component analysis, whole blood platelet aggregometry, and activated clotting time (ACT) were used to monitor compliance to therapy and identify any differences between donor groups. Clot kinetics and strength were analyzed using thrombelastography (TEG). Field Emission Scanning Electron Microscopy (FESEM) was used to analyze clot structure.

Results: Blood component profiles were similar for both donor groups. Aggregometry indicated that aggregation response to adenosine diphosphate (ADP) for clopidogrel donors was $12 \%$ of that for the controls $(p=0.0021)$, an expected result of clopidogrel induced platelet inhibition. However, blood from both donor groups had an elevated thrombin induced aggregation response. Heparinization of donor blood resulted in similarly elevated ACTs for both donor groups. TEG results indicated similar clot kinetics and strength between clopidogrel and control donor groups for blood alone and when clotting was induced using thrombin based gelatin matrices and fibrin sealants. FESEM images supported TEG findings in that similar morphologies were observed in ex vivo formed clots from both donor groups when thrombin based gelatin matrices and fibrin sealants were used.
\end{abstract}

Conclusion: These results suggest that platelet inhibitors do not negatively impact clot kinetics, strength, and structure when clotting is initiated with thrombin based gelatin matrices and fibrin sealants.

Keywords: Floseal, Tisseel, Clopidogrel, Thrombelastography, Thrombin, Hemostasis

\section{Background}

Platelets contribute to physiological hemostasis by aggregating at the site of a lesion, providing surfaces for hemostatic reactions, and supplying regulatory hemostatic factors. They also contribute to atherosclerotic disease by stimulating and stabilizing thrombi. Following myocardial infarction or stroke, the American Heart Association and American College of Cardiology guidelines recommend that patients take platelet inhibitors to reduce the risk of

\footnotetext{
* Correspondence: joseph-dwyer@sbcglobal.net

Deceased

'Baxter Healthcare Corporation, Deerfield, IL, USA

Full list of author information is available at the end of the article
}

further atherothrombotic events [1,2]. Clopidogrel and aspirin (acetylsalicylic acid) are commonly used platelet inhibitors. Both drugs reduce mortality in patients with chronic atherosclerotic disease and are also effective drugs for the acute treatment of infarcts [3].

Platelet aggregation is disrupted by these inhibitors via two distinct pathways. Clopidogrel acts as an inhibitor of adenosine diphosphate (ADP) induced platelet aggregation by covalently binding to its receptor, $\mathrm{P}_{2} \mathrm{Y}_{12}$. ADP mediated activation of the GPIIb/IIIa complex is therefore abated [4-6]. Aspirin irreversibly inhibits cyclooxygenase enzymes, COX1 and COX2 [7]. This prevents the conversion of arachidonic acid to thromboxane $A_{2}$ 
and subsequent thromboxane stimulated platelet aggregation $[8,9]$. Clopidogrel and aspirin can be used individually or in combination for dual anti-platelet therapy.

Several clinical studies have linked the use of platelet activation inhibitors to increased bleeding during surgery resulting in excess blood loss, increased transfusion rates, and reoperation [10-13]. These findings led the authors of these studies to recommend that surgery be delayed if possible to allow patients to withdraw from anti-platelet therapy $[10,12]$. Clopidogrel and aspirin both irreversibly alter platelet function. As a result, platelet aggregation and bleeding time generally do not return to normal levels until 5 days after discontinuing usage when sufficient quantities of new unaffected platelets have been produced [14]. Recommendations for and optimal time interval between cessation of anti-platelet medications and surgery vary from 3-10 days [15-18].

Other studies have suggested that the risk of further atherothrombotic events outweighs the risk of increased bleeding during surgery and recommend that in certain situations patients remain on either aspirin or dual antiplatelet therapy throughout the perioperative period $[19,20]$. For example, patients who are at an intermediate or high risk for cerebro- or cardiovascular events are recommended to remain on both clopidogrel and aspirin during many types of surgeries such as orthopedic surgery, reconstructive surgery, and endoscopy [19]. Consequently, many patients are undergoing surgical procedures with significant platelet inhibition as a result of a reluctance or inability (i.e. non-elective/emergency procedures) to withhold anti-platelet therapy prior to surgery. In such cases, surgeons face concerns that adjunctive thrombin based gelatin matrix and fibrin sealant hemostatic agents may not work effectively for patients on anti-platelet therapy.

Gelatin matrices and fibrin sealants that contain a thrombin component have been used for many years as effective adjunctive hemostats in surgery [21,22]. Both exogenous hemostats stop bleeding by inducing physiological hemostasis in a number of distinct ways. They curtail bleeding on tissue surfaces by generating fibrin mediated blood clots. As thrombin based gelatin matrices rely on incoming blood to supply the substrates for hemostatic clots, one potential clinical concern is that these hemostats may not work effectively for patients taking platelet aggregation inhibitors such as clopidogrel and aspirin. They also provide a high dose of thrombin, novel topologies, and substrates for blood and tissue derived factors to regulate hemostasis, and, in the case of thrombin based gelatin matrix hemostats, the gelatin particles provide a tamponade effect at the wound site, as well as contact activation, which leads to platelet activation.

The purpose of this study was to evaluate clots formed when thrombin based gelatin matrices and fibrin sealants were mixed with heparinized blood from patients who were taking clopidogrel to determine whether there was a negative impact of this platelet activation inhibitor on clot kinetics, strength, and/or structure. Assays employing whole blood were selected where appropriate for sample testing to more closely reflect the surgical conditions during application of the hemostats. Clot kinetics and strength were analyzed using thrombelastography (TEG) and clot structure was analyzed using Field Emission Scanning Electron Microscopy (FESEM). TEG was deemed an appropriate assay since it uses whole human blood, and it has been used to monitor patient hemostasis profiles during cardiac and general surgery $[23,24]$.

\section{Methods}

\section{Donor criteria and collection of whole blood}

Donor samples were collected from individuals in accordance with Baxter Healthcare's Internal Review Board. Blood was collected from three donors on clopidogrel and aspirin and one donor on only clopidogrel. Blood was also taken from four age matched control donors who were not taking clopidogrel or aspirin (i.e. control). The small number of donors is a consequence of the limited available donor pool and selection criteria (Table 1). These criteria were used isolate the impact of clopidogrel on hemostat performance from other drugs or medical conditions that interfere with hemostasis. The first $2-3 \mathrm{ml}$ of blood collected was discarded from each donor. Thereafter, $25 \mathrm{ml}$ of blood was collected in sodium citrate (3.2\%). An additional $5 \mathrm{ml}$ aliquot was collected in EDTA $(1.5 \mathrm{mg} / \mathrm{ml})$. The blood collected in EDTA was used for analysis of the blood cells, platelets, hematocrit, and hemoglobin. Other analyses were performed using citrated blood. All researchers performing the assays were blinded to donor status throughout the course of the study.

\section{Blood component analyses}

To investigate possible non-pharmaceutical related differences between the donor groups, a series of blood analyses were performed. Red and white blood cells, platelets, hemoglobin, and hematocrit were quantified for each donor sample with an ADVIA 2120 Hematology System (Siemens Corporation; Malvern, PA) using an aliquot of whole blood freshly collected in EDTA. The remaining blood analyses were performed using plasma prepared by centrifugation of citrated whole blood. The plasma was stored at $-80^{\circ} \mathrm{C}$. Fibrinogen concentration was measured using a STA Compact Hemostasis System (Diagnostica Stago; Parsippany, NJ), Factor VIII activity was measured using a Behring Coagulation System (Siemens Corporation; Malvern, PA), and Factor XIII levels were measured by ELISA (AssayPro; St. Charles, MO). 
Table 1 Inclusion and exclusion criteria for donors

\begin{tabular}{|c|c|c|}
\hline Inclusion criteria for clopidogrel donors & Inclusion criteria for age matched control donors & Exclusion criteria \\
\hline $\begin{array}{l}\text { Clopidogrel or clopidogrel and aspirin use } \\
\text { for at least } 14 \text { days prior to blood draw }\end{array}$ & $\begin{array}{l}\text { No clopidogrel use for at least } 14 \text { days } \\
\text { prior to blood draw }\end{array}$ & $\begin{array}{l}\text { History of diabetes, renal failure, acute or } \\
\text { chronic liver disease, including acute or } \\
\text { chronic hepatitis or cirrhosis }\end{array}$ \\
\hline $\begin{array}{l}\text { If on aspirin, daily aspirin dosage of at } \\
\text { least } 75 \mathrm{mg} / \text { day }\end{array}$ & $\begin{array}{l}\text { No aspirin use for at least } 14 \text { days prior } \\
\text { to blood draw }\end{array}$ & Positive for HIV, hepatitis B, or hepatitis C \\
\hline Males and Females & Males and Females & $\begin{array}{l}\text { Use of Selective Serotonin Re-uptake } \\
\text { Inhibitors (SSRIs), Seritonin-Norepinepherin } \\
\text { Re-uptake Inhibitors (SNRIs), Omeprazole } \\
\text { (which interferes with clopidogrel } \\
\text { metabolism) [25], or oral anticoagulants } \\
\text { (Coumadin, Warfarin, etc.) }\end{array}$ \\
\hline
\end{tabular}

\section{Whole blood platelet aggregometry}

Platelet aggregation induced by either ADP $(10 \mu \mathrm{M}$ final concentration, Chrono-Log Corporation; Havertown, PA.) or Thrombin (1 IU/ml final concentration, Baxter Healthcare Corporation; Deerfield, IL) was assessed in citrated whole blood on both clopidogrel and control donors. A Model 560VS Dual Channel Whole Blood LumiAggregometer (Chrono-log; Havertown, PA) using an impedance technique was used for testing each sample in duplicate per agonist, with the duplicates being averaged to obtain a final result.

\section{Blood heparinization and activated clotting time (ACT)}

Heparin (APP Pharmaceuticals, LLC; Schaumburg, IL) was added to each citrated whole blood sample to achieve a final concentration of $5 \mathrm{U} / \mathrm{ml}$ prior to TEG and imaging in order to assess the blood under clinically relevant heparin levels [26]. An Activated Clotting Time (ACT) measurement was taken of each blood sample before and after adding heparin using a Hemochron Response Whole Blood Coagulation System (International Technidyne Corporation; Edison, NJ). Because citrated blood was used for these measurements, calcium chloride was added to each test sample immediately prior to ACT analysis to return calcium ion concentration to a sufficient level to overcome the chelating effect of the sodium citrate.

\section{Thrombelastography (TEG)}

\section{TEG background}

Clot kinetics and strength were measured using a Thrombelastograph 5000 (Haemoscope Corporation; Niles, IL). TEG measurements were taken from citrated whole blood, heparinized blood, heparinized blood that was mixed with a thrombin based gelatin matrix (Floseal VH S/D: Baxter Healthcare Corporation; Deerfield, IL), and heparinized blood mixed with fibrin sealant (Tisseel VH S/D: Baxter Healthcare Corporation; Deerfield, IL). A sufficient level of calcium ion to overcome the chelating effect of sodium citrate was supplied by the thrombin component of each hemostat which was reconstituted in calcium chloride so no further calcium supplementation was needed. The clotting process as monitored by the TEG is reported as a set of coagulation parameters (Table 2).

\section{TEG analysis with citrated and heparinized blood alone}

The cup \& pin were loaded onto the TEG. Calcium chloride solution $(20 \mu \mathrm{l})$ was added to the cup. Citrated or heparinized blood $(340 \mu \mathrm{l})$ was then added to the cup, and the TEG analysis was immediately initiated. Donor samples were analyzed in triplicate.

\section{Preparation of the thrombin based gelatin matrix for TEG analysis}

Floseal VH S/D is a bovine-derived gelatin matrix that is prepared with human thrombin and indicated for hemostasis when control of bleeding by ligature or conventional procedures is ineffective or impractical [27]. Three lots of thrombin based gelatin matrix were prepared per IFU

\section{Table 2 Evaluated TEG coagulation parameters}

\begin{tabular}{|c|c|}
\hline Coagulation parameter & Description \\
\hline R-time (R) & $\begin{array}{c}\text { The time from the start of a sample run } \\
\text { until the first significant levels of } \\
\text { detectable clot formation in } \\
\text { minutes (min). }\end{array}$ \\
\hline K-time $(K)$ & $\begin{array}{l}\text { The time from the measurement of } R \\
\text { until a fixed level of clot firmness is } \\
\text { reached (Amplitude }=20 \mathrm{~mm} \text { ) in } \\
\text { minutes (min). }\end{array}$ \\
\hline Angle (a) & $\begin{array}{c}\text { An indicator of the kinetics of clot } \\
\text { formation and fibrinogen level } \\
\text { quantified in degrees }\left({ }^{\circ}\right) .\end{array}$ \\
\hline Maximum Amplitude (MA) & $\begin{array}{l}\text { A measurement of maximum } \\
\text { strength or stiffness of the developed } \\
\text { clot in millimeters ( } \mathrm{mm} \text { ) and an } \\
\text { indicator of platelet function. }\end{array}$ \\
\hline $\begin{array}{l}\text { Shear Elastic Modulus } \\
\text { Strength }(\mathrm{G})\end{array}$ & $\begin{array}{c}\text { A measurement of clot strength } \\
\text { calculated as } G=(5000 \mathrm{~A} /(100-\mathrm{A})) / 1000 \\
\text { and reported as dynes per square } \\
\text { centimeter }(\mathrm{d} / \mathrm{sc}) \text {. }\end{array}$ \\
\hline Time to MA (TMA) & $\begin{array}{l}\text { The time until the maximal clot strength } \\
(M A) \text { is reached in minutes (min). }\end{array}$ \\
\hline
\end{tabular}


(instructions for use) but on a reduced scale. The gelatin ( $0.100 \mathrm{~g}$ or $\sim 1 / 8$ of a $5 \mathrm{ml}$ kit syringe) was weighed out on weigh paper and then back-loaded into a $1 \mathrm{ml}$ tuberculin syringe. To remove air, the granules were compressed towards the luer end of the syringe. In a second tuberculin syringe, $0.5 \mathrm{ml}$ of $500 \mathrm{IU} / \mathrm{ml}$ thrombin solution was withdrawn (prepared by adding $5 \mathrm{ml} \mathrm{CaCl} 2$ to the thrombin vial) and a syringe connector was attached (luer end facing up). The two syringes were connected (one with gelatin and one with thrombin solution) and 'swooshed' at least 20 times to mix the gelatin and thrombin solution adequately.

\section{TEG analysis with thrombin based gelatin matrix}

The cup \& pin were loaded onto the TEG. The cup was subsequently removed from the TEG. The TEG cup was placed on the scale and the weight was zeroed. The first $100 \mu \mathrm{l}$ of mixed thrombin based gelatin matrix was discarded from the syringe. The tip of the syringe was cleaned with a Kimwipe to ensure that no excess thrombin based gelatin matrix remained. Using the tuberculin syringe, $150 \mu \mathrm{l}$ of the mixed thrombin based gelatin matrix was placed at the bottom of the TEG cup. The weight of the added thrombin based gelatin matrix was recorded. If the weight was $0.1160 \mathrm{~g}$ to $0.1260 \mathrm{~g}$, the sample was used. If not, the weight was adjusted so that the weight of sample in the cup was in this range. The cup was impacted against the lab bench several times to concentrate the thrombin based gelatin matrix evenly on the bottom of the cup. Heparinized blood $(210 \mu \mathrm{l})$ was added to the cup and mixed quickly with the thrombin based gelatin matrix using a pipette tip. The cup was then loaded onto the TEG with analysis initiated immediately. Donor samples were analyzed in triplicate with each of the three lots of thrombin based gelatin matrix.

\section{Preparation of the fibrin sealant for TEG analysis}

Tisseel VH S/D is a human-derived fibrin sealant indicated for hemostasis in surgeries involving cardiopulmonary bypass and treatment of splenic injuries due to blunt or penetrating trauma when control of bleeding by conventional techniques is ineffective or impractical [28]. Three lots of fibrin sealant were prepared per IFU. The fibrinogen and

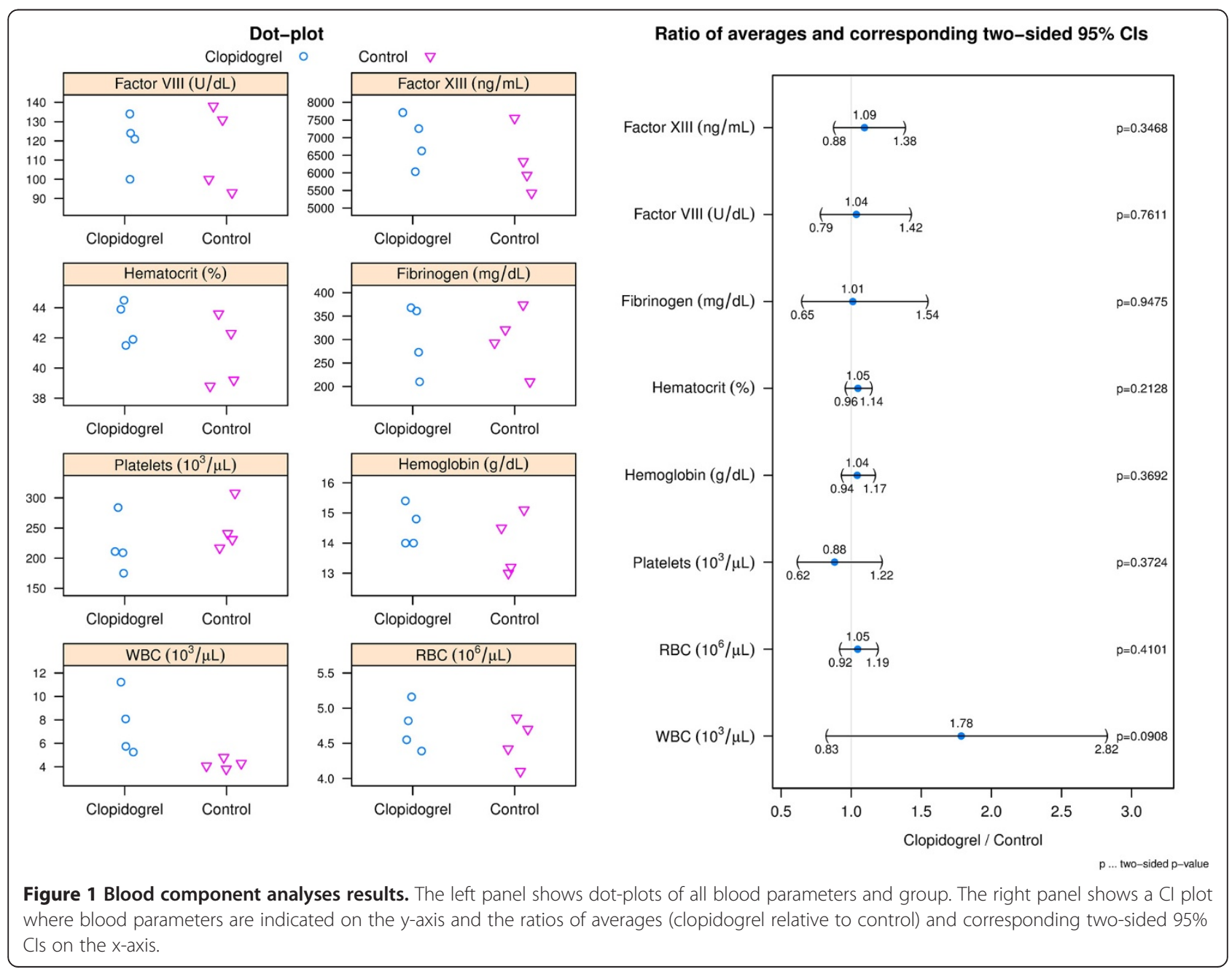


aprotinin components were warmed to $37^{\circ} \mathrm{C}$, and the $40 \mathrm{mM} \mathrm{CaCl}_{2}$ was brought to room temperature. The fibrinogen was reconstituted in aprotinin (F.C. $\sim 100 \mathrm{mg} / \mathrm{ml}$ ). The re-suspended fibrinogen was placed in a Fibrinotherm (Baxter Healthcare Corporation; Deerfield, IL) until dissolved and stored at $37^{\circ} \mathrm{C}$ until used. The thrombin was reconstituted in $40 \mathrm{mM} \mathrm{CaCl}_{2}$ (F.C. $\sim 500 \mathrm{IU} / \mathrm{ml}$ ) and stored at room temperature until used.

\section{TEG analysis with fibrin sealant}

The cup \& pin were loaded onto the TEG. The cup was subsequently removed from the TEG. Heparinized blood $(210 \mu \mathrm{l})$ was added to the cup. Fibrinogen solution (75 $\mu \mathrm{l}, \sim 7.5 \mathrm{mg})$ and thrombin solution $(75 \mu \mathrm{l}, \sim 37.5 \mathrm{IU})$ were added to the TEG cup simultaneously in conjunction with the blood volume above to total $360 \mu$ l. The sample was mixed quickly using a pipette tip and the cup loaded into the TEG. TEG analysis was immediately initiated. Donor samples were analyzed in triplicate with each of the three lots of fibrin sealant.
Field emission scanning electron microscopy (FESEM) Preparation of thrombin based gelatin matrix clots

The thrombin based gelatin matrix was prepared per IFU as indicated above and $150 \mu \mathrm{l}$ was dispensed into a well of a 24 well plate. Heparinized blood $(210 \mu \mathrm{l})$ was added to the well and the blood and hemostat were quickly mixed. The clot was allowed to set for $30 \mathrm{mi}-$ nutes at $37^{\circ} \mathrm{C}$ before the addition of $2 \mathrm{ml} /$ well of phosphate buffered saline (PBS). Clots were subsequently detached from the bottom of each well. After another 30 minutes at $37^{\circ} \mathrm{C}$, the clot was rinsed with $1 \mathrm{ml}$ PBS and fixed overnight at $4^{\circ} \mathrm{C}$ in $2 \mathrm{ml}$ of $2 \%$ glutaraldehyde (Electron Microscopy Sciences; Hatfield, PA) in $0.1 \mathrm{M}$ HEPES buffer.

\section{Preparation of fibrin sealant clots}

The fibrinogen and thrombin components of the fibrin sealant were prepared per IFU as indicated above. Heparinized blood $(210 \mu \mathrm{l})$ was added to the well of a 24 well plate followed by $75 \mu \mathrm{l}$ of fibrinogen solution and $75 \mu \mathrm{l}$

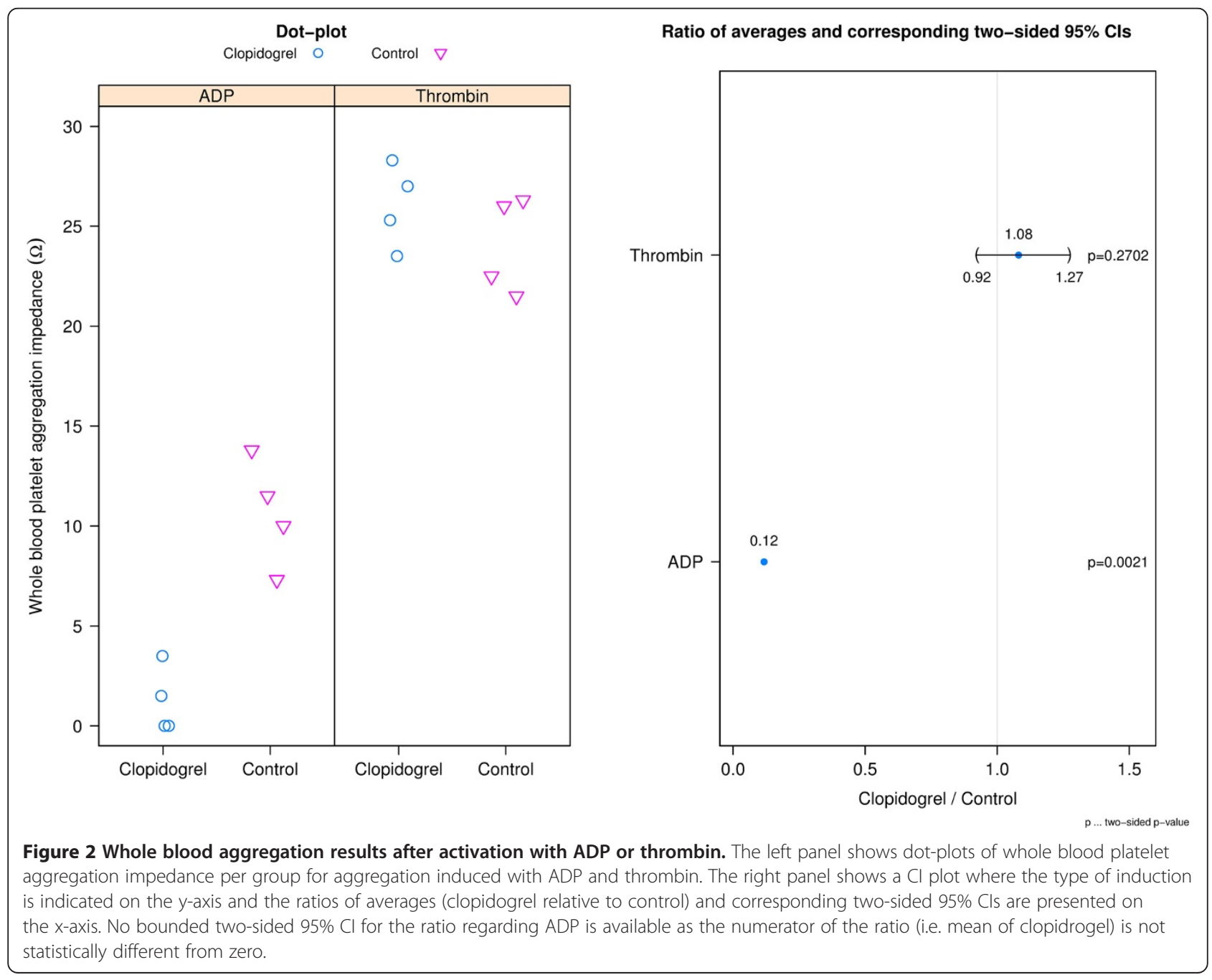


of thrombin solution. The blood and hemostat were quickly mixed and the clot was allowed to set for $30 \mathrm{mi}-$ nutes at $37^{\circ} \mathrm{C}$. Two milliliters of PBS were added to the well and the clot was detached from the bottom of the well. After another 30 minutes at $37^{\circ} \mathrm{C}$, the clot was rinsed with $1 \mathrm{ml} \mathrm{PBS}$ and fixed overnight at $4^{\circ} \mathrm{C}$ in $2 \mathrm{ml}$ of $2 \%$ glutaraldehyde in $0.1 \mathrm{M}$ HEPES buffer.

\section{Preparation of clots for FESEM}

After clot fixation, clots were rinsed with 0.1 M HEPES buffer and dehydrated in a graded ethanol (EtOH) series to $100 \% \mathrm{EtOH}$. The specimens were placed into 2:1, 1:1, and 1:2 solutions of $100 \% \mathrm{EtOH}$ to hexamethyldisilazane (HMDS, Electron Microscopy Sciences; Hatfield, PA), rinsed three times in 100\% HMDS followed by a quick change of 100\% HMDS, and allowed to air dry. The specimens were then mounted onto FESEM stubs affixed with double-stick conductive carbon tape and sputter coated with palladium in a Desk IV Sputter/Etch Unit (Denton Vacuum; Moorestown, NJ). The samples were examined in a JSM-6300 F FESEM (JEOL; Tokyo, Japan) and representative areas were recorded as digital images.

\section{Statistical analyses}

Comparison of clopidogrel versus control results was considered to be exploratory; therefore, analysis focused on estimation of group effects using confidence intervals (CIs) rather than on hypothesis testing. All analyses were performed with R version 2.15.3 (R Core Team; Vienna, Austria) [29].

\section{Blood analysis}

Differences in blood parameters between clopidrogel and control donors were assessed using ratios of averages, corresponding two-sided 95\% CIs, and two-sided p-values obtained by R function "t.test.ratio (option var. equal = FALSE)" of R package "mratios" [30].

\section{Thrombelastography}

TEG data were analyzed using a linear mixed effects model taking the replicate measurements per donor adequately into account. The model consisted of the fixed effect group (clopidogrel and control) and donor as random effects, and was fitted using $\mathrm{R}$ function "lme" of $R$ package "nlme" [31]. Differences in TEG data

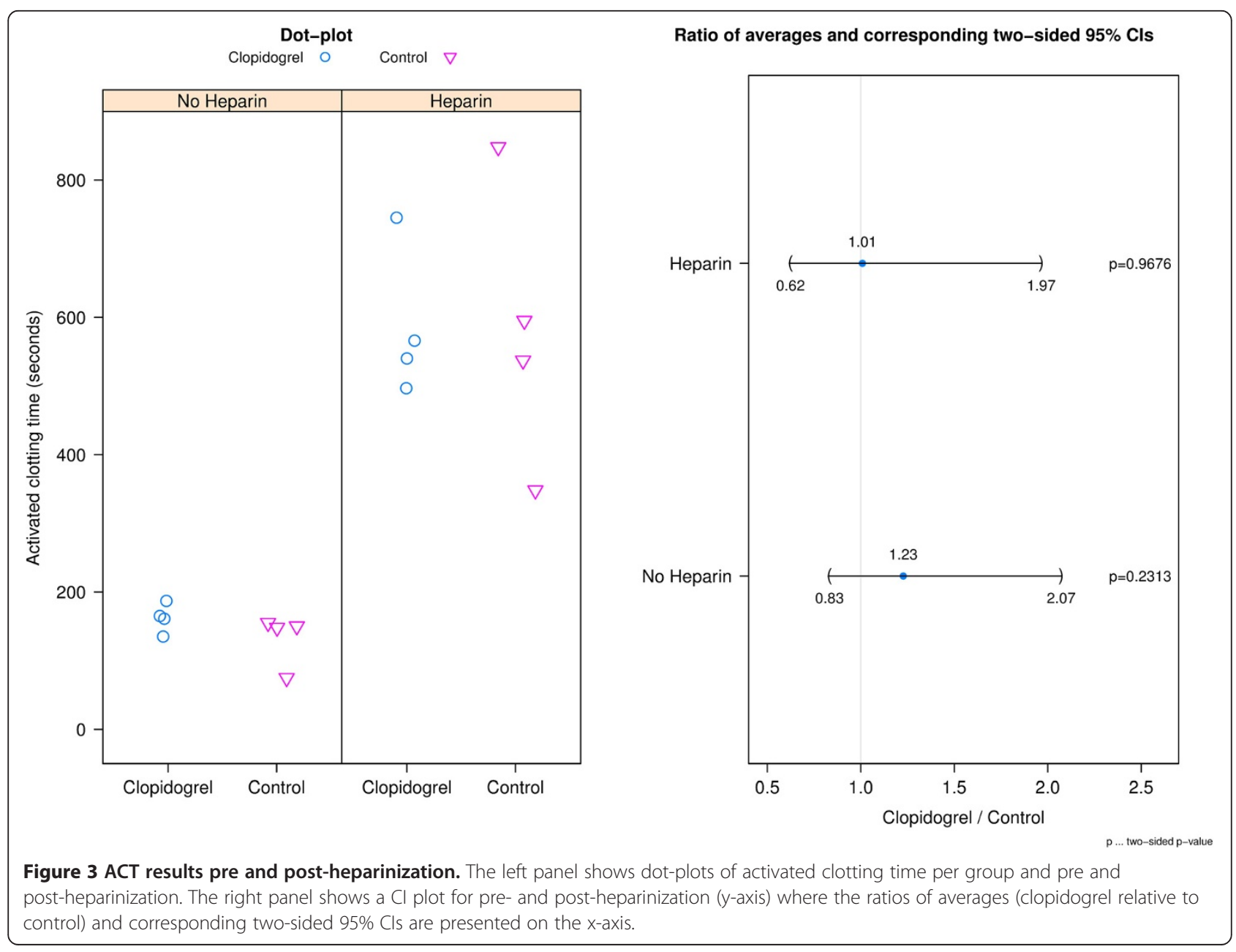


between clopidogrel and control donors were assessed using ratios of averages, corresponding two-sided 95\% CIs and two-sided p-values where the two-sided 95\% CI for the ratio of averages were obtained using Fieller's theorem [32].

\section{Results}

\section{Donor criteria}

Four clopidogrel donors and four control donors that met the set criteria were used for this study. The four clopidogrel donors were taking clopidogrel daily and three of the four donors were also taking daily aspirin. The control donors had not taken clopidogrel or aspirin for at least 14 days prior to blood collection. The median age of clopidogrel and control donors was 55 (range: 47 to 62 ) and 55 (range: 50 to 58 ) years, respectively.

\section{Blood component analyses}

The results of the blood component analyses were similar between donor groups (Figure 1). The largest difference between donor groups was observed in WBC with a 1.78 (95\% CI: 0.83 to 2.82) times higher average WBC count for clopidogrel donors than for control donors; however, this difference was not statistically significant at the $5 \%$ level.

\section{Whole blood platelet aggregometry}

Average aggregation response to adenosine diphosphate (ADP) for clopidogrel donors was $12 \%$ of that for the controls $(p=0.0021)$ (Figure 2). However, when thrombin was used as the agonist on the same blood obtained from the same donors, the platelet aggregation response was normalized with a 1.08 (95\% CI: 0.92 to 1.27$)$ times larger average response for clopidogrel donors.

\section{Activated clotting time (ACT)}

The addition of heparin to the each donor's blood resulted in an expected increase in ACT (Figure 3). On average, clopidogrel donors had a 1.23 (95\% CI: 0.83 to 2.07 ) and 1.01 (95\% CI: 0.62 to 1.97) times longer ACT before and after addition of heparin, respectively.

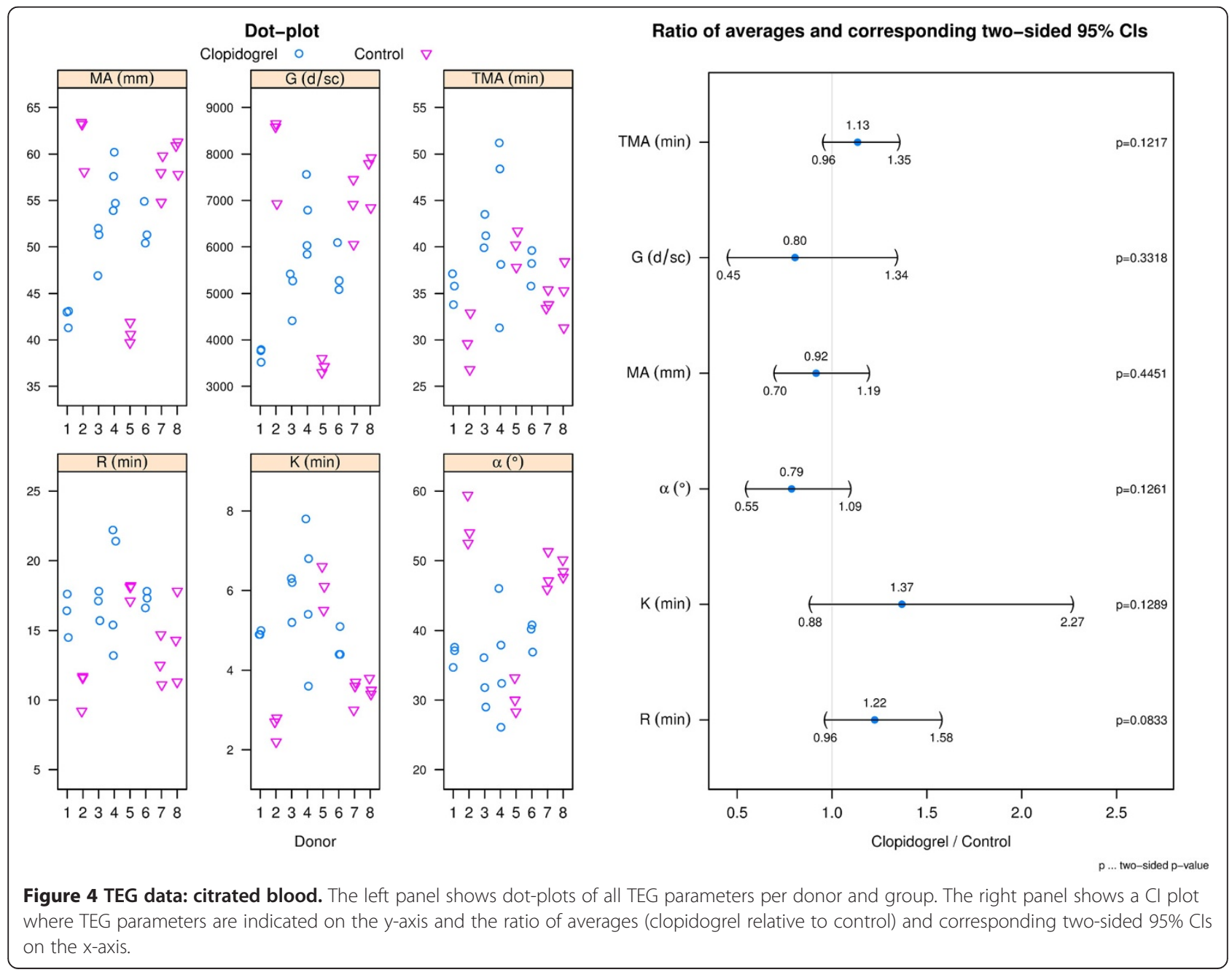




\section{Thrombelastography (TEG)}

\section{Citrated and heparinized blood alone}

TEG data for citrated blood (Figure 4) indicates that across all TEG parameters there is a trend which suggests that clopidogrel may impede hemostasis; however differences between donor groups did not reveal statistical significance at the $5 \%$ level for any of the parameters. Heparinized blood alone samples did not clot for any donor and were stopped after 45 minutes in the TEG (data not shown).

\section{Thrombin based gelatin matrix and fibrin sealant}

TEG parameter results for the thrombin based gelatin matrix (Figure 5) and fibrin sealant (Figure 6) mixed with donor blood were similar between donor groups based on the ratios of averages.

\section{FESEM of thrombin based gelatin matrix and fibrin sealant clots}

Images of thrombin based gelatin matrix clots (Figure 7) from both donor groups appeared morphologically similar.
The fibrin structure had similar fiber thickness, branching, and porosity. Clots generated with the fibrin sealant (Figure 8) also had similar morphology for both donor groups.

\section{Discussion}

In this study, clopidogrel had no significant impact on the kinetics and visco-elastic clot strength of whole blood clots formed ex vivo. This result is consistent with the relative low risk of bleeding observed in patients taking clopidogrel [14]. Perhaps clopidogrel has a bigger mechanistic impact on a plaque stimulated thrombus than it has on disrupting physiological hemostasis due to differences in temporal activation, sequence of thrombin activation, or the relative greater importance of platelets.

Blood component measurements indicated similar results between clopidogrel and control donors with the exception of average WBC count which was 1.78 (95\% CI: 0.83 to 2.82 ) times higher for clopidogrel donors

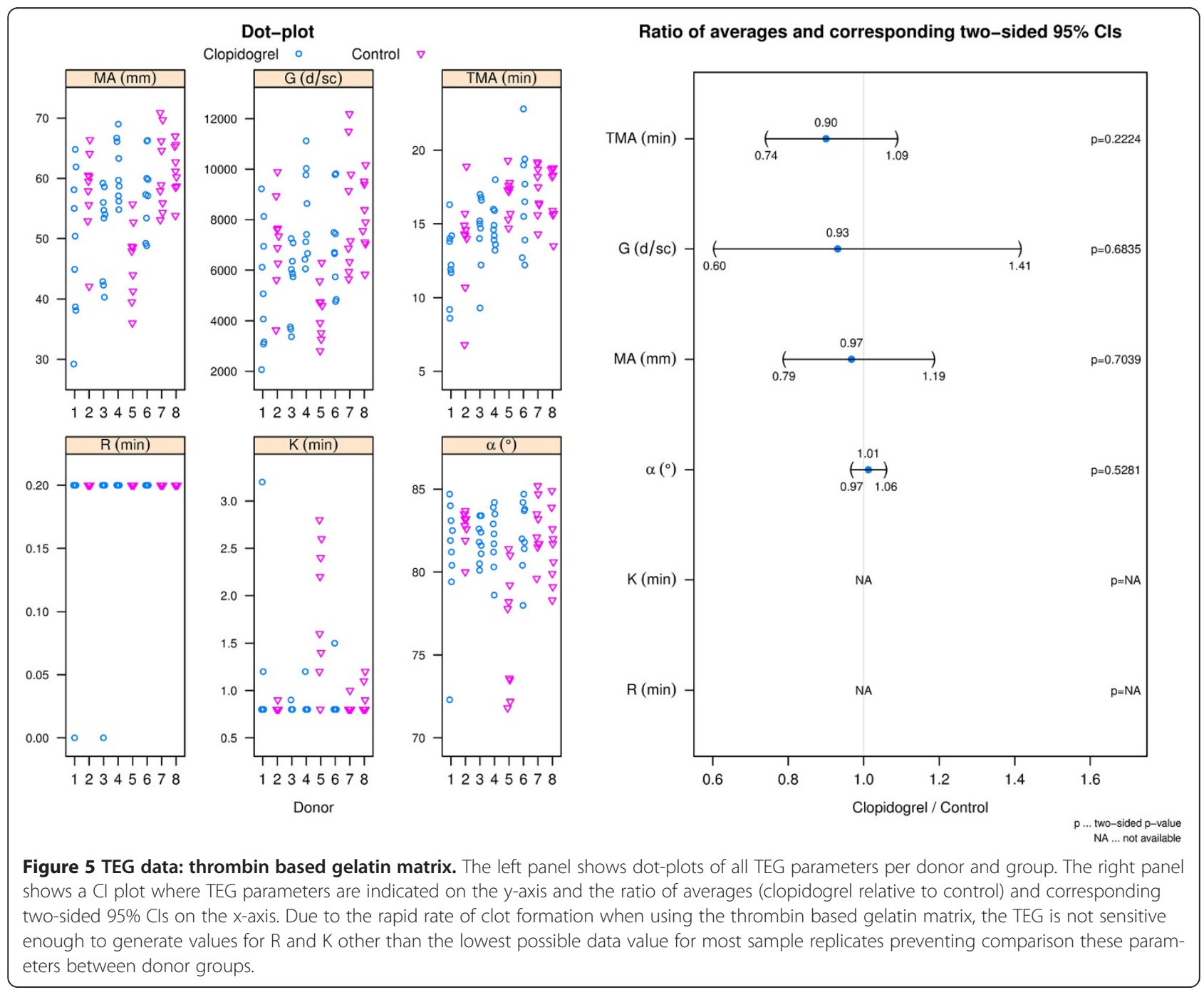




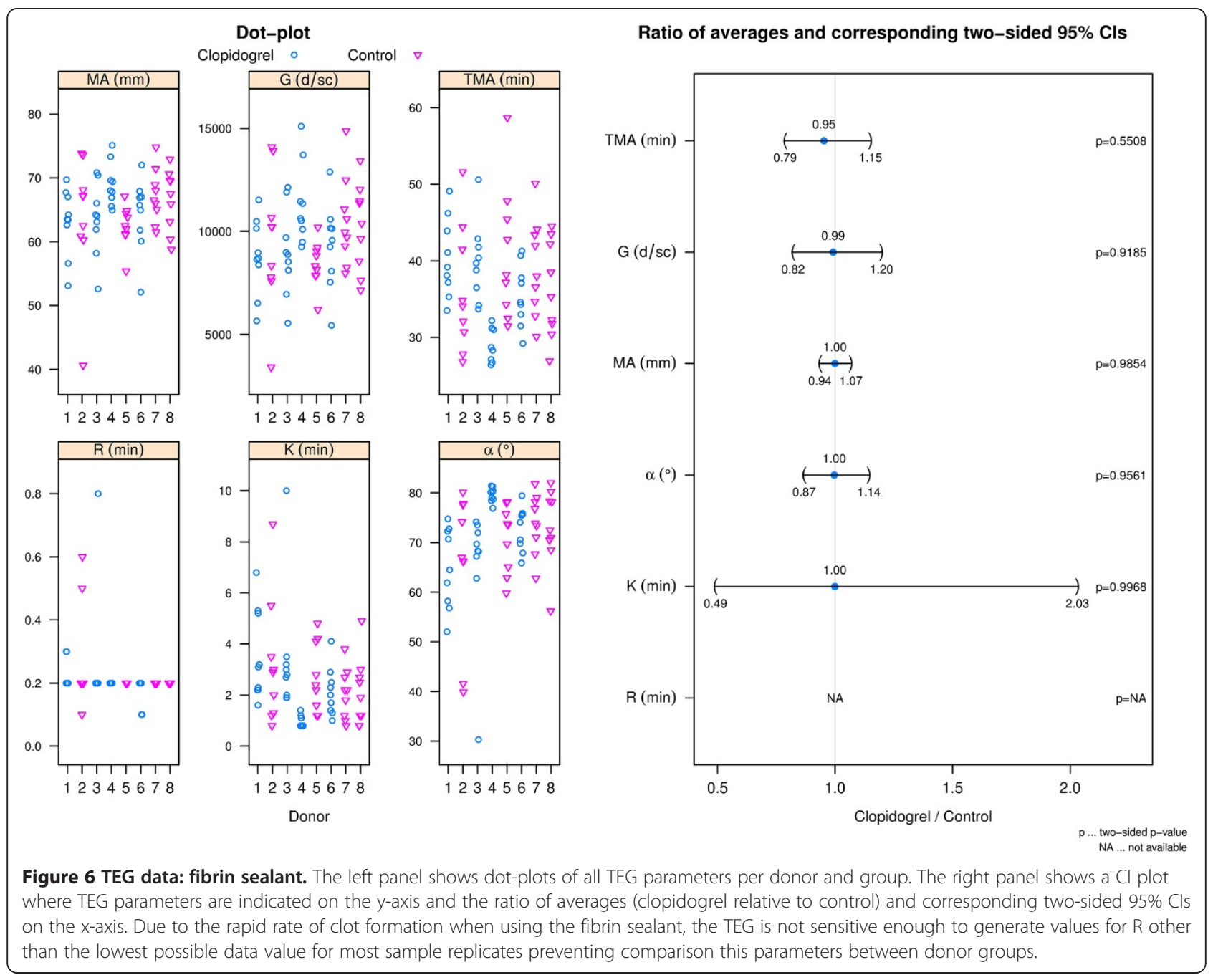

than for control donors. Further assessment by analysis of covariance of the difference in blood aggregation after activation with ADP and thrombin between donor groups adjusted for potential differences in WBC count resulted in two-sided $\mathrm{p}$-values of $\mathrm{p}=0.0046$ and $\mathrm{p}=0.3908$ respectively leading to the same statistical conclusion as without using WBC count as a covariate (Figure 2). The similarity in remaining blood parameter measurements reduces the likelihood that a difference in another coagulation factor or blood component influenced aggregation response to adenosine diphosphate or thrombin. The averages for ACT before and after addition of heparin were similar between both donor groups. However, the addition of heparin to the blood samples did elevate the clotting time to clinically relevant values. The average clotting times for both donor groups were between 550 and 600 seconds following addition of heparin compared to averages below 200 seconds at baseline. ACTs between 300 and 600 seconds are described as the 'safe zone' for patients undergoing extracorporeal circulation [33] while the ACT for cardiac surgery can be targeted at 350 seconds or greater [34].

Although platelets are important for hemostasis, our results using this ex vivo model suggest that impaired platelet activation does not impact the effectiveness of gelatin matrices and fibrin sealants incorporating the use of thrombin. An explanation for this finding comes from one of our assays used to monitor patient compliance to therapy. A statistically significant difference at the $5 \%$ level was detected using ADP activated whole blood aggregometry which demonstrated that the clopidogrel donors had defective platelet activation compared to the control donors. This result also indicates that the donors do not harbor the polymorphism in the CYP2C19 gene that renders them poor clopidogrel responders because they do not aggregate in response to ADP [35]. However, when thrombin was used as the agonist, the average whole blood aggregometry results for clopidrogel donors were similar to that for control donors. Whole blood aggregometry is a well-established 


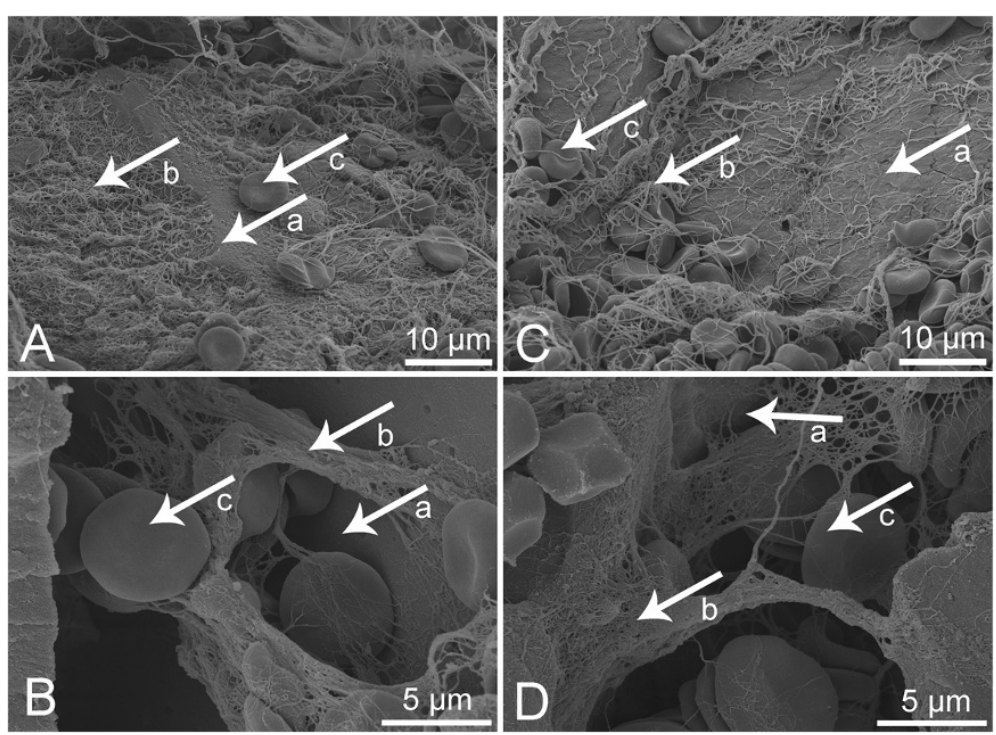

Figure 7 Representative images of thrombin based gelatin matrix clots acquired with FESEM. Control (A,B), clopidogrel (C,D); $10 \mu \mathrm{m}$ scale bars (A,C), 5 um scale bars (B,D); Arrows: Gelatin (a), Fibrin (b), Red Blood Cells (c). No qualitative differences were observed in the fibrin structure (porosity, fiber thickness, and branching) or the cellular accumulation around the gelatin granules including large numbers of trapped RBCs between clopidogrel and control donor groups.

method to measure platelet function and has been found to correlate well with clinical outcome [36,37]. Therefore, these data demonstrate that thrombin can initiate platelet aggregation in platelets that are unable to respond to ADP due to clopidogrel blockade of the $\mathrm{P} \mathrm{Y}_{12}$ receptor.

The high concentration of thrombin in the thrombin based gelatin matrix and the fibrin sealant hemostats provides a possible explanation for the lack of impact of clopidogrel on their efficacy. The scientific literature supports this conclusion in that thrombin is the most potent activator of platelets and does so through a different signal transduction pathway than ADP. Thrombin activates platelets through the Par1/Par4 and GpI 7 receptors [38]. Once the signaling pathway is initiated, activation propagates though PI3 kinase and GPIIb/IIIa leading to platelet aggregation and an increase in intraplatelet calcium concentration [39]. Thus, thrombin may not only play a central role in controlling bleeding, but may also restore normal clot kinetics and strength when used in combination with gelatin matrix and fibrin sealant hemostats in patients who use prophylactic clopidogrel as a platelet aggregation inhibitor. TEG analysis of blood from donors using prophylactic clopidogrel found no detectable impact on hemostasis stimulated by either gelatin matrix or fibrin sealant hemostats which contain thrombin when compared to the control donors. This is consistent with the platelet aggregation results and clot structure analysis.

Morphological characterization of clots formed when thrombin based gelatin matrix and fibrin sealant hemostats were mixed with donor blood supports the quantitative

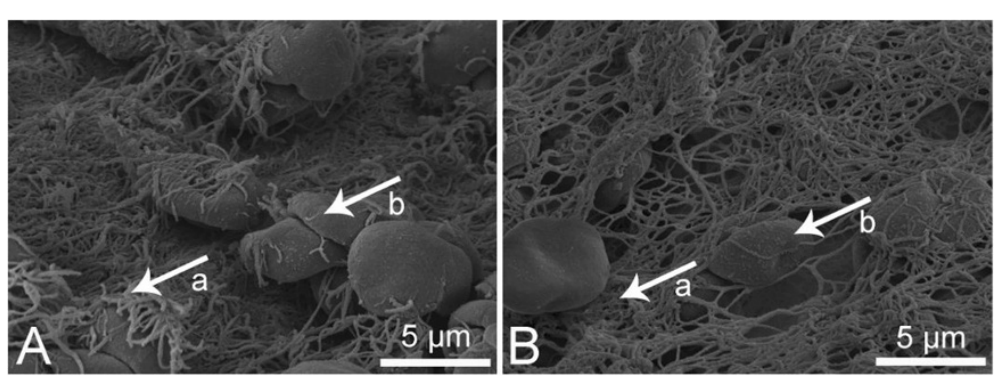

Figure 8 Representative images of fibrin sealant clots acquired with FESEM. Control (A), clopidogrel (B); $5 \mu$ m scale bars; Arrows: Fibrin (a), Red Blood Cells (b). As seen in the images of the thrombin based gelatin matrix clots, no qualitative differences were observed between clopidogrel and control donor groups. The density of the fibrin structure seen compared to the gelatin based hemostat clots may be due to the additional fibrinogen supplied by the fibrin sealant. 
data accumulated during this study. Although differences can be seen with FESEM based on the type of hemostat used, the fibrin morphology and incorporation of red blood cells between clots formed with clopidogrel donor blood and those of the controls were similar. The clots formed with fibrin sealant were similar to those seen previously $[40,41]$ as well as those formed with the thrombin based gelatin matrix hemostat [42]. Therefore, not only does the use of thrombin attenuate the impact of clopidogrel by initiating platelet activation while retaining normal clot kinetics and strength, it also facilitates structurally similar clots when used in combination with gelatin matrix and fibrin sealant hemostats. However, this indicates only the potential to form a structurally adequate clot in vivo considering the artificial nature in which the clots were created ex vivo.

Whole blood was selected for testing in that it more closely reflects the conditions during surgical application of the thrombin based gelatin matrix and fibrin sealant hemostats, but there are considerations that must be addressed due to the presence of high concentration thrombin in the hemostats. While thrombin is a potent stimulator of platelets, it is also responsible for converting fibrinogen to fibrin, a reaction which also influences whole blood platelet aggregometry and TEG results. In the case of whole blood platelet aggregometry, the thrombin concentration had to be reduced from the kit concentration of $500 \mathrm{IU} / \mathrm{ml}$ to $1 \mathrm{IU} / \mathrm{ml}$. For the purposes of simplicity it was also referred to as to platelet aggregometry even though a coagulation reaction was known to have occurred. The same can be said for the TEG assay in that the high concentration of thrombin in the hemostats elicited the same reaction making it unlikely to discern between coagulation and platelet aggregation effects by this method. However, these tests were not designed to imply a direct comparative basis for ADP stimulated platelet aggregation to thrombin stimulated platelet aggregation or to discern between coagulation and platelet aggregation effects but to evaluate the effectiveness of the hemostats when used with donor blood in which platelets were inhibited by clopidogrel.

Based on these data, thrombin based gelatin matrices and fibrin sealants are likely to be effective when used during surgical procedures involving patients currently on clopidogrel anti-platelet therapy. This is consistent with recent clinical trial data demonstrating the effectiveness of a fibrin sealant based hemostat in patients on platelet inhibitors [43]. Despite the clinically meaningful results of this study, it was limited in scope and designed to encourage additional clinical studies to verify the basic findings of this work. The small patient numbers are the main limitation of this exploratory study, reducing the power of the statistical analysis to detect differences. Therefore, analysis focused on estimation rather than on hypothesis testing. Lack of clinical correlations with this study's TEG data is another obvious limitation. However, other research using a rabbit bleeding model to show that clopidogrel had no impact on the bleeding rate in vivo [44] is consistent with results in human blood presented in this paper.

This study also raises some interesting questions. In the modern era of poly-pharmacy, the impact of multiple medications such as SSRIs, SNRIs, platelet inhibitors, thrombin inhibitors, and Vitamin $\mathrm{K}$ antagonists as well as congenital deficiencies in hemostatic factors may have unpredictable consequences on the regulation of hemostasis. Consequently, surgical hemostats may have to be carefully evaluated in the context of this growing combinatorial complexity.

\section{Conclusion}

The use of thrombin based gelatin matrices and fibrin sealants initiated clot formation when mixed with blood from donors on anti-platelet therapy that was similar to that of control donor blood within the constraints of the TEG assay. This study provided a basis for future investigation into the effectiveness of thrombin based hemostats during surgical procedures involving patients on anti-platelet therapy.

\section{Abbreviations}

a: Angle; ACT: Activated clotting time; ADP: Adenosine diphosphate; Cl: Confidence interval; FESEM: Field emission scanning electron microscopy; G: Shear elastic modulus strength; IFU: Instructions for use; K: Clotting time; MA: Maximum amplitude; R: Reaction time; RBC: Red blood cell;

SNRI: Seritonin-norepinepherin re-uptake inhibitor; SSRI: Selective serotonin re-uptake inhibitor; TEG: Thrombelastography; TMA: Time to MA; WBC: White blood cell.

\section{Competing interests}

The authors of this manuscript are current or former employees and consultants of Baxter Healthcare Corporation.

\section{Authors' contributions}

JFD was responsible for blood sample labeling and distribution, development and execution of TEG assays, organization of data for statistical analysis, drafting and submission of the manuscript, and was involved in study design. JAM was responsible for study design, maintaining the blind for the study, donor recruitment, and was involved in the drafting of the manuscript. ZY was involved in the study design, preparations of clots for FESEM, and assay execution. MH was responsible for the development and execution of the hematological assays. HR was involved in the study design and development of particle based TEG assay. MM was involved in the processing of clots for FESEM. MW was responsible for the statistical analysis. JPD was responsible for FESEM. AG was involved in study design. SD was involved in study design and drafting of the manuscript. All authors contributed to, read, and approved the final manuscript.

\section{Acknowledgements}

The authors dedicate this publication to the memory of Shane Donovan, Ph. D. so that his work lives on. The authors would also like to thank Huub Kreuwel, Ph.D., Megan Francis-Sedlak, Ph.D., and Kevin Lewis, DVM for their assistance in completing this publication and Anna Khadem for her assistance on the particle based TEG assay. 


\section{Author details}

${ }^{1}$ Baxter Healthcare Corporation, Deerfield, IL, USA. ${ }^{2}$ Ludwig Boltzmann Institute for Experimental and Clinical Traumatology, AUVA Research Center Austrian Cluster for Tissue Regeneration, Vienna, Austria. ${ }^{3}$ Baxter Innovations $\mathrm{GmbH}$, Wagramerstrasse 17-19, 1220 Wien, Austria.

Received: 12 September 2013 Accepted: 21 April 2014

Published: 7 May 2014

\section{References}

1. Krumholz HM, Anderson JL, Bachelder BL, Fesmire FM, Finn SD, Foody JM, Ho PM, Kosiborod MN, Masoudi FA, Nallamothu BK, Masoudi FA, Bonow RO, DeLong E, Estes NAM, Goff DC, Grady K, Green LA, Loth A, Peterson ED, Radford MJ, Rumsfeld JS, Shahian DM: ACC/AHA 2008 performance measures for adults with ST-elevation and non-ST-elevation myocardial infarction: a report of the American College of Cardiology/American Heart Association Task Force on Performance Measures (writing committee to develop performance measures for ST-elevation and non-ST-elevation myocardial infarction): developed in collaboration with the American Academy of Family Physicians and the American College of Emergency Physicians: endorsed by the American Association of Cardiovascular and Pulmonary Rehabilitation, Society for Cardiovascular Angiography and Interventions, and Society of Hospital Medicine. Circulation 2008, 118:2596-2648.

2. Adams RJ, Albers G, Alberts MJ, Benavente O, Furie K, Goldstein LB, Gorelick P, Halperin J, Harbaugh R, Johnston SC, Katzan I, Kelly-Hayes M, Kenton EJ, Marks M, Sacco RL, Schwamm LH: Update to the AHA/ASA recommendations for the prevention of stroke in patients with stroke and transient ischemic attack. Stroke 2008, 39:1647-1652.

3. Faxon DP: Use of antiplatelet agents and anticoagulants for cardiovascular disease: current standards and best practices. Rev Cardiovasc Med 2005, 6(Suppl 4):S3-S14.

4. Gachet C, Stierle A, Cazenave JP, OhImann P, Lanza F, Bouloux C, Maffrand JP: The thienopyridine PCR 4099 selectively inhibits ADP-induced platelet aggregation and fibrinogen binding without modifying the membrane glycoprotein IIb-Illa complex in rat and in man. Biochem Pharmacol 1990 40:229-238

5. Savi P, Labouret C, Delesque N, Guette F, Lupker J, Herbert JM: P2y(12), a new platelet ADP receptor, target of clopidogrel. Biochem Biophys Res Commun 2001, 283:379-383.

6. Savi P, Laplace MC, Herbert JM: Evidence for the existence of two different ADP-binding sites on rat platelets. Thromb Res 1994, 76:157-169.

7. Vane JR, Botting RM: The mechanism of action of aspirin. Thromb Res 2003, 110:255-258.

8. Tohgi H, Konno S, Tamura K, Kimura B, Kawano K: Effects of low-to-high doses of aspirin on platelet aggregability and metabolites of thromboxane A2 and prostacyclin. Stroke 1992, 23:1400-1403.

9. Patrignani P, Filabozzi P, Patrono C: Selective cumulative inhibition of platelet thromboxane production by low-dose aspirin in healthy subjects. J Clin Invest 1982, 69:1366-1372.

10. Badreldin A, Kroener A, Kamiya H, Lichtenberg A, Hekmat K: Effect of clopidogrel on perioperative blood loss and transfusion in coronary artery bypass graft surgery. Interact Cardiovasc Thorac Surg 2010, 10:48-52

11. Herman CR, Buth KJ, Kent BA, Hirsch GM: Clopidogrel increases blood transfusion and hemorrhagic complications in patients undergoing cardiac surgery. Ann Thorac Surg 2010, 89:397-402.

12. Nurozler F, Kutlu T, Kucuk G, Okten C: Impact of clopidogrel on postoperative blood loss after non-elective coronary bypass surgery. Interact Cardiovasc Thorac Surg 2005, 4:546-549.

13. Sun JC, Whitlock R, Cheng J, Eikelboom JW, Thabane L, Crowther MA, Teoh KH: The effect of pre-operative aspirin on bleeding, transfusion, myocardial infarction, and mortality in coronary artery bypass surgery: a systematic review of randomized and observational studies. Eur Heart J 2008, 29:1057-1071

14. Bristol-Meyers Squib/Sanofi Pharmaceuticals: Plavix (Clopidogrel Bisulfate) Tablet, Film Coated. Bridgewater, NJ; 2009.

15. Billett HH: Antiplatelet agents and arterial thrombosis. Cardiol Clin 2008, 26:189-201. vi.

16. Ferrari E, Benhamou M, Cerboni P, Marcel B: Coronary syndromes following aspirin withdrawal: a special risk for late stent thrombosis. J Am Coll Cardiol 2005, 45:456-459.
17. Vasudeva P, Goel A, Sengottayan VK, Sankhwar S, Dalela D: Antiplatelet drugs and the perioperative period: what every urologist needs to know. Indian J Urol 2009, 25:296-301.

18. Weber AA, Braun M, Hohlfeld T, Schwippert B, Tschope D, Schror K: Recovery of platelet function after discontinuation of clopidogrel treatment in healthy volunteers. Br J Clin Pharmacol 2001, 52:333-336.

19. Chassot PG, Delabays A, Spahn DR: Perioperative antiplatelet therapy: the case for continuing therapy in patients at risk of myocardial infarction. Br J Anaesth 2007, 99:316-328.

20. O'Riordan JM, Margey RJ, Blake G, O'Connell PR: Antiplatelet agents in the perioperative period. Arch Surg 2009, 144:69-76. discussion 76.

21. Emilia M, Luca S, Francesca B, Luca B, Paolo S, Giuseppe F, Gianbattista B, Carmela M, Luigi M, Mauro L: Topical hemostatic agents in surgical practice. Transfus Apher Sci 2011, 45:305-311.

22. Oz MC, Rondinone JF, Shargill NS: FloSeal matrix: new generation topical hemostatic sealant. J Card Surg 2003, 18:486-493.

23. Kaufmann CR, Dwyer KM, Crews JD, Dols SJ, Trask AL: Usefulness of thrombelastography in assessment of trauma patient coagulation. J Trauma 1997, 42:716-720. discussion 720-712.

24. Tuman KJ, McCarthy RJ, Djuric M, Rizzo V, Ivankovich AD: Evaluation of coagulation during cardiopulmonary bypass with a heparinase-modified thromboelastographic assay. J Cardiothorac Vasc Anesth 1994, 8:144-149.

25. Ferreiro JL, Ueno M, Capodanno D, Desai B, Dharmashankar K, Darlington A, Charlton RK, Bass TA, Angiolillo DJ: Pharmacodynamic effects of concomitant versus staggered clopidogrel and omeprazole intake: results of a prospective randomized crossover study. Circ Cardiovasc Interv 2010, 3:436-441.

26. Hardy JF, Belisle S, Robitaille D, Perrault J, Roy M, Gagnon L: Measurement of heparin concentration in whole blood with the Hepcon/HMS device does not agree with laboratory determination of plasma heparin concentration using a chromogenic substrate for activated factor $\mathrm{X}$. J Thorac Cardiovasc Surg 1996, 112:154-161.

27. Baxter Healthcare Corporation: FloSeal Hemostatic Matrix. Hayward, CA; 2009.

28. Baxter Healthcare Corporation: TISSEEL [Fibrin Sealant]. Westlake Village, CA; 2009.

29. R-Core Team: R: A Language and Environment for Statistical Computing. [http://www.R-project.org/]

30. Dilba G, Hasler M, Gerhard D, Schaarschmidt F: mratios: Inferences for Ratios of Coefficients in the General Linear Model. R Package Version 1.3.17. [http://CRAN.R-project.org/package=mratios].

31. Pinheiro J, Bates D, DebRoy S, Sarkar D, R Development Core Team: nlme: Linear and Nonlinear Mixed Effects Models. R Package Version 3.1-108. [http://CRAN.R-project.org/package=nlme].

32. Fieller EC: Some problems in interval estimation. J R Stat Soc Ser B 1954, 16:175-185

33. Bull MH, Huse WM, Bull BS: Evaluation of tests used to monitor heparin therapy during extracorporeal circulation. Anesthesiology 1975, 43:346-353.

34. Fitzgerald DJ, Patel A, Body SC, Garvin S: The relationship between heparin level and activated clotting time in the adult cardiac surgery population. Perfusion 2009, 24:93-96

35. Hulot JS, Bura A, Villard E, Azizi M, Remones V, Goyenvalle C, Aiach M, Lechat P, Gaussem P: Cytochrome P450 2C19 loss-of-function polymorphism is a major determinant of clopidogrel responsiveness in healthy subjects. Blood 2006, 108:2244-2247

36. Agarwal S, Coakley M, Reddy K, Riddell A, Mallett S: Quantifying the effect of antiplatelet therapy: a comparison of the platelet function analyzer (PFA-100) and modified thromboelastography (mTEG) with light transmission platelet aggregometry. Anesthesiology 2006, 105:676-683.

37. Ivandic BT, Schlick P, Staritz P, Kurz K, Katus HA, Giannitsis E: Determination of clopidogrel resistance by whole blood platelet aggregometry and inhibitors of the P2Y12 receptor. Clin Chem 2006, 52:383-388.

38. Kahn ML, Nakanishi-Matsui M, Shapiro MJ, Ishihara H, Coughlin SR: Protease-activated receptors 1 and 4 mediate activation of human platelets by thrombin. J Clin Invest 1999, 103:879-887.

39. Voss B, McLaughlin JN, Holinstat M, Zent R, Hamm HE: PAR1, but not PAR4, activates human platelets through a Gi/o/phosphoinositide-3 kinase signaling axis. Mol Pharmacol 2007, 71:1399-1406

40. Macasev D, Diorio JP, Gugerell A, Goppelt A, Gulle H, Bittner M: Cell compatibility of fibrin sealants: in vitro study with cells involved in soft tissue repair. J Biomater Appl 2011, 26:129-149. 
41. Furst $W$, Banerjee $A$, Redl $H$ : Comparison of structure, strength and cytocompatibility of a fibrin matrix supplemented either with tranexamic acid or aprotinin. J Biomed Mater Res B Appl Biomater 2007, 82:109-114.

42. DiOrio JP, Stojanovic L, Yardimci A, Amrani DL, Helgerson S, Vega F: Electron microscopic characterization of a gelatin matrix/thrombin hemostat. Microsc Microanal 2005, 11:178-179.

43. Saha SP, Muluk S, Schenk W 3rd, Dennis JW, Ploder B, Grigorian A, Presch I, Goppelt A: A prospective randomized study comparing fibrin sealant to manual compression for the treatment of anastomotic suture-hole bleeding in expanded polytetrafluoroethylene grafts. J Vasc Surg 2012 56:134-141.

44. Hughes SD, Bishop PD, Garcia R, Zhang T, Alexander WA: Topical recombinant thrombin at a concentration of $1000 \mathrm{IU} / \mathrm{mL}$ reliably shortens in vivo $\mathrm{TTH}$ and delivers durable hemostasis in the presence of heparin anticoagulation and clopidogrel platelet inhibition in a rabbit model of vascular bleeding. Ann Surg Innov Res 2009, 3:14.

doi:10.1186/1477-9560-12-10

Cite this article as: Dwyer et al:: Thrombin based gelatin matrix and fibrin sealant mediated clot formation in the presence of clopidogrel.

Thrombosis Journal 2014 12:10.

\section{Submit your next manuscript to BioMed Central and take full advantage of:}

- Convenient online submission

- Thorough peer review

- No space constraints or color figure charges

- Immediate publication on acceptance

- Inclusion in PubMed, CAS, Scopus and Google Scholar

- Research which is freely available for redistribution 